Daniel Alonso ORCID iD: 0000-0003-3605-4679

\title{
Epidemiological description, case-fatality rate, and trends of Hantavirus Pulmonary Syndrome: 9 years of surveillance in Argentina.
}

\author{
Authors: \\ D.O. ALONSO ${ }^{1}$, A. IGLESIAS ${ }^{1}$, R. COELHO ${ }^{1}$, N. PERIOLO ${ }^{1}$, A. BRUNO ${ }^{2}$, M.T. \\ CÓRDOBA $^{2}$, N. FILOMARINO ${ }^{3}$, M. QUIPILDOR ${ }^{2}$, E. BIONDO ${ }^{4}$, E. \\ FORTUNATO $^{5}$, C.M. BELLOMO ${ }^{1}$, V.P. MARTÍNEZ ${ }^{1 *}$. \\ Affiliations: \\ ${ }^{1}$ Instituto Nacional de Enfermedades Infecciosas - Administración Nacional de \\ Laboratorio e Institutos de Salud (ANLIS) “Dr. C.G. Malbrán”, Ciudad Autónoma de \\ Buenos Aires, Argentina. \\ ${ }^{2}$ Hospital San Vicente de Paúl, Orán, Salta, Argentina. \\ ${ }^{3}$ Hospital Señor Del Milagro, Salta, Argentina. \\ ${ }^{4}$ Ministerio de Salud de la Provincia de Chubut, Argentina. \\ ${ }^{5}$ Ministerio de Salud de la Provincia de Buenos Aires, Buenos Aires, Argentina.
}

\section{Address for Correspondence.}

Valeria Paula Martinez, Instituto Nacional de Enfermedades Infecciosas - ANLIS

“Dr. C.G. Malbran”, Av. Velez Sarsfield 563, Buenos Aires, CP. 1281, Argentina.

Tel/Fax: 5411 4301-3146 pmartinez@anlis.gov.ar

This article has been accepted for publication and undergone full peer review but has not been through the copyediting, typesetting, pagination and proofreading process, which may lead to differences between this version and the Version of Record. Please cite this article as doi: 10.1002/jmv.25446.

This article is protected by copyright. All rights reserved. 


\title{
Running Head:
}

Epidemiology of HPS in Argentina.

\section{Key words:}

Epidemiology, zoonotic, virology, Andes virus, Hantavirus, Hantavirus Pulmonary Syndrome

\begin{abstract}
:
Hantavirus pulmonary syndrome (HPS) is an endemic disease in Argentina, one of the most affected countries in the Americas. Andes virus (ANDV) is the main Orthohantavirus species causing HPS in Argentina. In this work, the geographical distribution, clinical presentation, and epidemiological features of HPS from all endemic regions of Argentina were analysed. We focused on the clinical and epidemiological data from 533 HPS cases confirmed during the period 2009 to 2017 by the National Reference Laboratory for Hantavirus (NRLH). A case-fatality rate of 21.4\% was registered, and most of the cases presented a severe clinical picture requiring intensive care treatment (84\%). In order to analyse HPS case-fatality rate trends in Argentina since its first detection in 1995 all laboratory-confirmed casepatients were considered, showing a general trend towards a decrease. After more than 22 years of experience in HPS diagnosis and surveillance, we discuss some possible factors implicated in this tendency. This clinical and epidemiological analysis gives a global perspective, being useful to detect trends and patterns, in order to update preventive actions at a national level and evaluate their impact on public health.
\end{abstract}

This article is protected by copyright. All rights reserved. 


\section{Introduction}

Hantaviruses include human pathogens responsible for hemorrhagic fever with renal syndrome (HFRS) in Europe and Asia and hantavirus pulmonary syndrome (HPS) in the Americas, respectively ${ }^{1,2}$. The first pathogenic American hantavirus was characterized in the southwestern United States in 1993 after an unusual outbreak of respiratory disease in the Four Corners region ${ }^{3,4}$. Two years later a similar outbreak occurred in the Andean region of Patagonia, Argentina, leading to the characterization of Andes virus (ANDV) ${ }^{5,6}$.

Hantaviruses are tri-segmented-RNA viruses belonging to the Hantaviridae family, Orthohantavirus genus ${ }^{7}$, and are maintained in nature by small mammals (rodents, shrew, moles, bats) and their transmission occurs ex-vivo without intermediate vectors. These viruses establish persistent infections in several species of rodents and insectivores ${ }^{8}$.

After the description of ANDV and its rodent reservoir, Oligoryzomys longicaudatus, several variants of this virus were confused with new orthohantaviral species because they were identified in different rodent species ${ }^{5,9}$. However, further genetic analysis has demonstrated that the aminoacidic divergence among them was not enough to consider them as separate viral species ${ }^{10-12}$. It is noteworthy that ANDV is the causative agent of almost all HPS cases in Argentina ${ }^{10,13}$; the only exception is Laguna Negra virus (LNV), which was identified in very few HPS cases in the Northwest region ${ }^{14}$. The variants or genotypes of ANDV are differently distributed among each endemic region in the country. All pathogenic genotypes of ANDV found in Argentina have in common that their reservoir hosts belong to the Oligoryzomys genus.

This article is protected by copyright. All rights reserved. 
The main mechanism for humans to become infected is by inhaling aerosolized excreta from reservoir hosts ${ }^{15}$. However, ANDV is also capable of person-to-person transmission, a mechanism that makes it unique among hantaviruses ${ }^{16-18}$. After an incubation period of up to 40 days, HPS begins with a febrile phase indistinguishable from other viral prodromes ${ }^{19}$. At the end of this phase, which can last from 3 to 6 days, dry cough and dyspnoea typically appear. This marks the beginning of the cardiopulmonary phase characterized by pulmonary edema due to capillary leakage, with a typically abrupt progress that can be followed by cardiogenic shock in few hours. ANDV, like other American hantaviruses, is considered one of the most lethal human pathogens ${ }^{19-21}$. A major problem is that there are no vaccines or therapeutics approved to prevent or ameliorate this devastating disease ${ }^{22}$.

Although HPS was firstly described in the early 1990`s in the Americas, it is still considered an emerging disease due to the ongoing process of the discovery of novel hantaviruses, and the cyclic reemergence of certain orthohantavirus species in clusters or outbreaks of human infections ${ }^{2}$. HPS emergence is thought to be driven mainly by socio-economic and environmental factors, such as unfavorable working conditions in rural areas and precarious housing, and unpredictable changes in rodent populations. The aim of this study was to present an extensive description of the epidemiological situation of HPS in Argentina, to accurately determine the region of infection of patients with travel records inside the country and to establish case fatality rates and tendencies in the period 2009-2017.

\section{Methods}

HPS case definition. A suspected case was defined as a patient who resides or report a recent travel history to an endemic region, with persistent fever ( $>48 \mathrm{hs}$ ) showing headache, myalgias and gastrointestinal manifestations (abdominal pain, vomiting 
and/or diarrhea), and a marked decrease in platelet count. This definition was particularly applicable to find patients during the earlier phase of the disease. In an advanced stage, also patients with any sign of respiratory compromise. Any febrile person who has been in contact during the previous 35 days with a recently laboratory-confirmed HPS case was also considered.

Study population. We analyzed blood samples from patients who met to the definition of suspected case from all the country during the period 2009-2017, which were received directly in the National Reference Laboratory (NRL) or through any of the provincial laboratories from the national laboratory network for hantavirus (NRLH).

Clinical severity classification. We were able to categorize 519 case-patients by their clinical picture severity using the classification criteria as previously described ${ }^{25}$. Briefly, Grade I for patients with prodromal symptoms without respiratory compromise; Grade II for patients with mild to moderate respiratory compromise without hemodynamic compromise; Grade III for patients with severe respiratory insufficiency with hemodynamic compromise; Grade IV for patients with severe respiratory insufficiency and refractory-to-treatment hemodynamic compromise with fatal outcome.

Study design. The epidemiological study presented here was a descriptive and retrospective analysis. HPS cases were classified according to the ordinal variable severity grades and described by the following nominal variables: sex, geographical regions (namely: Northwest, Northeast, Central, Cuyo, and Patagonia), clinical symptoms, and risk activities. Finally, we analysed age as a quantitative continuous variable.

This article is protected by copyright. All rights reserved. 
In order to study the risk activities we defined 4 categories of exposure in a period of 30 days before the onset of symptoms: Occupational, persons who performed activities related to their work; Recreational, persons who performed activities in wild environments or rural surrounding (camping, fishing, trekking, etc); Peridomestic, rural or suburban residents without defined events of exposure in other places, considering housing and the surrounding land the source of infectious rodents; Human-to-human transmission, persons who were in close contact with confirmed HPS case-patients ${ }^{17}$. Patients with travel records outside the country during their most probable exposure or patients with travel records to endemic areas out of Argentina were excluded from the analysis.

The diagnosis was performed on serum or blood samples from suspected cases detecting specific immunoglobulin (Ig)M by ELISA ( $\mu$-capture technique) and IgG against ANDV recombinant nucleoprotein (NP), which was developed and produced at the NRLH as previously described ${ }^{23}$.

Laboratory confirmation of HPS cases. Cases were laboratory-confirmed by the presence of both IgM and IgG antibodies; cases with IgM titres but not IgG were confirmed verifying IgG seroconversion in second samples and/or by viral RNA detection. ELISA techniques were validated using confirmed HPS sera from all regions of the country, in order to evaluate the specific response against all different circulating genotypes of ANDV and LNV. In the same way, 2 groups of samples were also tested for specificity: non-reactive sera for ANDV-NP and reactive sera for pathologies considered in the differential diagnosis for HPS (data not published).Diagnostic sensitivity and specificity parameters were determined by ROC curves for IgM and IgG, showing $96.6 \%$ and $90.6 \%$ values respectively. Viral RNA detection and genetic characterization were performed, when necessary, by 
quantitative RT-PCR (RT-qPCR) and RT-PCR followed by nucleotide sequencing respectively, as previously described ${ }^{10,24}$. RT-qPCR was used to quantify the S segment. RT-PCR was used to amplify partial genome sequences from the S segment and $\mathrm{M}$ segment coding regions.

Data analysis and Statistics. In order to study differences in the geographical distribution of cases, the Kruskal-Wallis test was performed. Case-fatality rate according to sex were compared by Fisher Exact test and Chi-square for trends was used to analyse the annual number of cases. Data was statistically analysed using GraphPad (Prism 6.0, GraphPadSoftware Inc. San Diego, CA). Geographic Information System QGIS “Las Palmas” (version 2.18.11, http://www.qgis.org/es/site/) was used to evaluate HPS case distribution in the country.

\section{Results}

\section{Diagnosis and laboratory confirmation}

The NRLH received 4488 samples from HPS suspected cases during the period 2009 - 2017, of which 533 HPS cases were laboratory confirmed (11.9\% of all suspected samples), around 59 cases per year, on average. Since HPS is a reportable disease, cases were notified through the National Health Surveillance System (SIVILA). Although 241 additional cases were reported through SIVILA by independent laboratories usually performing diagnostic tests not validated by the NRLH, those cases were not taken into account for this study. Standardized information was required for each suspected cases through HPS clinical/epidemiological forms. The overall case-fatality rate tendency was $21.4 \%$.In the present study, 94.2\% (502/533) of the samples sent for diagnosis had detectable levels of both IgM and IgG specific antibodies against ANDV. The remaining 5.8\% (31/533) were confirmed by direct 
viral genome detection. Some patients showed only IgG reactivity, but due to the absence of IgM, no seroconversion and no viral genome amplification ( $\mathrm{n}=51)$, were not considered as current acute HPS cases.

Time elapsed between onset of symptoms and sampling date was on average 5.9 days (median=5; $n=443$ ). For Northwest the median value was 4, $n=223$; Central $6, n=155$; Patagonia 5, $n=63$; Northeast $6, n=2$. The differences were statistically significant ( $<<0.0001$, Kruskal-Wallis test).

\section{Temporal and Geographical distribution of Cases}

The analysis of geographical distribution of cases showed that HPS were reported in 4 out of 5 geographical regions of the country: Northwest, Northeast, Central, and Patagonia, but not in Cuyo region (Table 1). Cases inside each region were restricted to relatively small areas as shown in Figure 1. The Northwest was the most affected, showing $48.7 \%$ of cases (260/533), followed by Central and Patagonia with $36.7 \%$ (196/533) and 14.1\% (75/533) respectively. Only 2 cases occurred in the Northeast region, $0.4 \%$ (Table 1 and 4).Seasonal distribution was marked, the warmer seasons being when more cases occurred; this distribution was consequently wider in the tropical region of the country (Figure $2 \mathrm{C}$ ). We observed a highly variable annual distribution with different patterns according to each region (Figure $2 \mathrm{~A}$ ). HPS affected all age groups, the age ranged from 0 to 86 years old (mean=32.5; median=31); $7.4 \%$ of cases were children ( $<14$ years of age). The youngest case was a 15-day-old newborn child who was probably infected by his mother, who was retrospectively classified as a suspected case based on clinical and epidemiological data after her death. Among the present case series, 78.7\% were male patients (Figure 3).

This article is protected by copyright. All rights reserved. 
The overall annual incidence ranged from 1.15 to 1.85 in the period, showing wide variations between regions: 9, 1 and 5 per 1000000 persons in Northwest, Central and Patagonia respectively. This analysis was performed on the basis of the last national census (www.indec.gov.ar).

\section{Clinical Characteristics}

Although the course of the disease was highly variable, most of the cases presented the typical clinical picture described for HPS. Most cases (99.4\%) were hospitalized, excluding 3 asymptomatic cases detected due to a study of contacts and some other patients showing only prodromal symptoms in the Northwest region. As shown in Table 2, 84.2\% (437/519) of cases developed a severe disease requiring intensive care (severity groups II, III and IV) and at least 31.4\% (163/519) of those cases required mechanical ventilation (III and IV). The prodromal phase was short, 3 to 5 days, followed by different degrees of respiratory compromise, usually acute distress with rapid progression to respiratory failure. Besides fever, the most frequent prodromal symptoms were headache, myalgia, arthralgia and conjunctival injection and retroocular pain. Gastrointestinal symptomatology was common and some patients showed abdominal pain even before any other prodromal symptoms.

Neurological manifestations were rarely reported (6.9\%), confusional syndrome being the most frequently observed, while some patients showed severe complications as convulsions and/or encephalitis (Table 3). Thrombocytopenia was present in 84\% of cases $($ Range 7,000 - 511,000 cells/ml; mean value $=70271 ; \mathrm{n}=426)$; and petechiae was also common. Other hemorrhagic manifestations were rarely observed.

\section{Case-fatality rate}

The overall case-fatality rate was $21.4 \%$ in this period and varied significantly between geographical regions showing an increasing trend southwards: Northwest

This article is protected by copyright. All rights reserved. 
(15\%), Central (23.9\%) and Patagonia (36\%) $(\mathrm{p}<0.0001$ Chi-square for trends) (Table 4). The Northeast region only reported 2 cases during this period, 1 of them being fatal. Although fatal outcome was higher for female, the difference by sex for the whole period was not significant (27.4\% vs 19.9\%) ( $\mathrm{p}<0.0936$ Fisher Exact test). The fatality rate of HPS per million population in the studied period was: 12 (Northwest); 2 (Central) and 15 (Patagonia). The age-adjusted fatality rate was 12.2; 1.8 and 13.9; respectively (Waterhouse standard population) and results similar to the crude casefatality rate.

\section{Exposure activities}

In order to study the risk activities associated with infection and according to information provided by clinical/epidemiological forms we classified 441 cases in the following rodent exposure groups: 55.8\% occupational, 14.3\% recreational, $28.1 \%$ peridomestic; the remaining $1.8 \%$ reported contact with previous cases and probable person-to-person transmissions (Table 4). The regional comparison showed that occupational exposures were most frequent in all regions, with the highest values in Northwest. This kind of exposures affected mainly rural workers, although other activities such as security personnel and truck drivers were also reported. Exposure to a previous confirmed HPS case was only reported in Central and Patagonia. These events of exposure were accurately analysed for most of the cases from the Central region in a previous work ${ }^{26}$.

The determination of the viral genotype helped to figure out the most probable site of infection in several patients who had a travel record history within the previous 30 days before the onset of symptoms (Table 5). One particular case was a patient who died in Buenos Aires City, Central region, but with rural exposure outside the known 
endemic area of the Northwest region. This allowed us to confirm the first case in Tucuman Province ${ }^{27}$.

\section{Discussion.}

In this work, we accurately analysed the epidemiological situation of more than 500 HPS case-patients in Argentina during a 9 year period and the tendency of casefatality rate since its first description. This analysis represented around 70\% of HPS reported cases in Argentina, 533 definitely confirmed HPS cases. A previous work of our group reported an average of 50.8 cases/year during the period 1995-2008, while during the present period the mean number of cases per year was 59.2, representing an increase of around $14 \%{ }^{19}$. We observed an expansion of the area of cases in the Northwest ${ }^{27}$. Cases have been reported in 12 out of 24 Argentine provinces since 1995. Although the most affected regions in number of cases were Northwest and Central regions, the highest rate of incidence per million persons was found in Patagonian region. Comparing these values for Argentina and the United States of America (USA), which ranged from 1.15 to 1.85 and 0.04 to 0.19 HPS cases/million persons respectively, Argentina showed at least 10 -fold higher incidence rate ${ }^{28}$. It is worth noting that the endemic Andean region in Patagonia is a particularly touristic zone where several infections led to the exportation of ANDV cases to other counties and/or non-endemic places in Argentina ${ }^{17,29,30}$. Furthermore, the current HPS-case distribution is not conclusive and it does not imply that other areas may be affected in the future. The presence of Oligoryzomys longicaudatus was predicted to be present with high probability by modelling approaches all along the Andean Mountains in Patagonia $^{31}$. Since this predicted host distribution area is wider than the HPS endemic area for ANDV-South, new endemic places could be expected in the future especially associated with demographic increments in human population. Nevertheless, 
considering the ex-vivo viral transmission mechanism, virus survival is probably restricted to high humid environments, beyond the natural presence of the host. Although the interannual variation was marked, there was a slight tendency towards increment of cases in the period, particularly in the Central region. Conversely, the notable decrease in the count during the last 2 years in the Northwest region marked a reduction trend there. It is noteworthy that HPS case number was relatively stable in the Patagonia region since during the study period a particular phenomenon took place all along the endemic area inside the region of Patagonian Forests: the flowering of the Colihue cane (Chusquea culeou) ${ }^{32}$. The overwhelming abundance of seeds is one of the causes for rodent population increasing. The prediction of this phenomenon allowed the implementation of preventive campaigns throughout the region, so its impact with an increase in human hantavirus infections could be avoided. The stable tendency in the occurrence of cases in this southern region of the country demonstrated the effectiveness of preventive measures to reduce rodent-human interaction in the area.

It is noteworthy the importance to perform studies at a national level because they give a global perspective of the disease. They are also useful to detect trends and to evaluate the impact of the already implemented measures at regional or even at a national level. HPS has been associated with high case fatality rates and is considered one of the most lethal viral diseases ${ }^{19,28,33-35}$. Only 2 countries performed previous case-series studies at a national level in The Americas spanning long periods of time: the USA and Argentina. In the USA during the period 1993-2009, there were reported 30 cases per year on average $(n=510)$ and the case fatality rate was $35 \%$. In Argentina, during a shorter period of 14 years, 710 cases were reported in the period 1995-2008 with an overall case-fatality rate of $25.8 \%{ }^{19,28}$. Adding the 533 new cases 
reported in the present work, a total of 1243 HPS laboratory confirmed cases were indentified during 22 years of surveillance in Argentina. During the present study period, the case-fatality rate in the entire country was $21.4 \%$, indicating a decrease compared to the previous period ${ }^{19}$. In spite of this, the clinical picture observed was moderate to severe, in general, requiring hospitalization in almost all patients. The decrease in case fatality rate could be explained by the cumulative medical experience in the supportive treatment for this pathology and/or the improved technology in respiratory assistance. It is noteworthy that the case-fatality rate was lower among patients treated in hospitals with previous experience in HPS treatment. Given the absence of preventive vaccines or specific therapeutic treatments for HPS, to turn case-fatality rate even lower, prompt transfer of patients to experienced and specialized centres in supportive treatments should be evaluated. On the other hand, differences in clinical picture and case-fatality rates between regions could also be related to unknown viral determinants among genotypes and/or differences in human population susceptibilities. To figure out its definite origin particular studies should be focused on both these aspects in the future.

Due to the variable and long incubation period of HPS, in which some cases reported multiple risk activities, to assess accurately the source of infection was very difficult. Analyzing the information related to the source of exposure, we identified that occupational activities were most frequently associated with HPS in each region and were mostly related to rural activities. This would indicate the need of preventive approaches, policies and/or employee education programs. Population with potential for frequent rodent exposure should be aware of the risks for hantavirus infection at their workplaces. On the other hand, exposures to previously confirmed cases were mostly reported in Patagonia (8\%), but few cases also occurred in the Central region 
(2\%), where ANDV- South and ANDV- BsAs genotypes were associated to well defined person-to-person transmission respectively ${ }^{17,26}$. Larger educational efforts should be carried on in order to reduce exposure risk in all categories.

Given the extensive territory of the country, our main limitation for a more accurate HPS surveillance was the non-standardized data obtained from each province. Misdiagnosis or incomplete diagnosis of HPS cases in Argentina was also an important limitation for our present analysis because independent laboratories reported around $30 \%$ of the suspected cases without the supervision of the NRLH, and could not be included in this analysis. The reinforcement of the Hantavirus National Laboratory Network, lead by the NRLH, adding new nodes that could perform a local (at the Provincial level) and early diagnosis with validated techniques will help to decrease misdiagnosis, to improve detection and, therefore, to improve survival of patients. This might be also useful to decrease underreporting in Argentina. A multidisciplinary public health effort will be required to improve surveillance, decrease underreporting of HPS, and carry out extensive reservoir studies all around the country to determine a complete risk map at a national level. This will help to design and conduct epidemiological studies and preventive measures at a national level.

\section{Acknowledgments.}

We appreciate the invaluable contributions of physicians and epidemiologists in data collection and continued support, which made this research possible.

\section{Financial Support.}

This work was supported by Instituto Nacional de Enfermedades Infecciosas ANLIS “Dr. C.G. Malbrán”. 


\section{Conflict of interest.}

None.

\section{References.}

1. Clement J, Heyman P, McKenna P, Colson P, Avsic-Zupanc T. The hantaviruses of Europe: from the bedside to the bench. Emerging infectious diseases. Apr-Jun 1997;3(2):205-211.

2. Schonrich G, Rang A, Lutteke N, Raftery MJ, Charbonnel N, Ulrich RG. Hantavirus-induced immunity in rodent reservoirs and humans. Immunol Rev. Oct 2008;225:163-189.

3. Nichol ST, Spiropoulou CF, Morzunov S, et al. Genetic identification of a hantavirus associated with an outbreak of acute respiratory illness. Science. Nov 5 1993;262(5135):914-917.

4. Sands L, Kioski C, Komatsu K. Hantavirus in the southwestern United States: epidemiology of an emerging pathogen. The Journal of the American Osteopathic Association. Dec 1993;93(12):1279-1285.

5. Lopez N, Padula P, Rossi C, Lazaro ME, Franze-Fernandez MT. Genetic identification of a new hantavirus causing severe pulmonary syndrome in Argentina. Virology. Jun 01 1996;220(1):223-226.

6. Lopez N, Padula P, Rossi C, et al. Genetic characterization and phylogeny of Andes virus and variants from Argentina and Chile. Virus research. Jul 1997;50(1):77-84.

7. Plyusnin A, Vapalahti O, Vaheri A. Hantaviruses: genome structure, expression and evolution. The Journal of general virology. Nov 1996;77 ( Pt 11):2677-2687.

8. Ermonval M, Baychelier F, Tordo N. What Do We Know about How Hantaviruses Interact with Their Different Hosts? Viruses. Aug 11 2016;8(8).

9. Levis S, Morzunov SP, Rowe JE, et al. Genetic diversity and epidemiology of hantaviruses in Argentina. The Journal of infectious diseases. Mar 1998;177(3):529-538.

10. Padula PJ, Colavecchia SB, Martinez VP, et al. Genetic diversity, distribution, and serological features of hantavirus infection in five countries in South America. Journal of clinical microbiology. Aug 2000;38(8):3029-3035.

11. Bohlman MC, Morzunov SP, Meissner J, et al. Analysis of hantavirus genetic diversity in Argentina: S segment-derived phylogeny. Journal of virology. Apr 2002;76(8):3765-3773.

12. Maes $\mathrm{P}, \mathrm{Klempa} B$, Clement J, et al. A proposal for new criteria for the classification of hantaviruses, based on $\mathrm{S}$ and $\mathrm{M}$ segment protein sequences. Infection, genetics and evolution : journal of molecular epidemiology and evolutionary genetics in infectious diseases. Sep 2009;9(5):813-820.

13. Martinez VP, Colavecchia S, Garcia Alay M, et al. [Hantavirus pulmonary syndrome in Buenos Aires Province]. Medicina. 2001;61(2):147-156.

14. Levis S, Garcia J, Pini N, et al. Hantavirus pulmonary syndrome in northwestern Argentina: circulation of Laguna Negra virus associated with Calomys callosus. The American journal of tropical medicine and hygiene. Nov 2004;71(5):658-663.

15. Jonsson CB, Figueiredo LT, Vapalahti O. A global perspective on hantavirus ecology, epidemiology, and disease. Clin Microbiol Rev. Apr 2010;23(2):412441.

This article is protected by copyright. All rights reserved. 
16. Padula PJ, Edelstein A, Miguel SD, Lopez NM, Rossi CM, Rabinovich RD. Hantavirus pulmonary syndrome outbreak in Argentina: molecular evidence for person-to-person transmission of Andes virus. Virology. Feb 15 1998;241(2):323-330.

17. Martinez VP, Bellomo C, San Juan J, et al. Person-to-person transmission of Andes virus. Emerging infectious diseases. Dec 2005;11(12):1848-1853.

18. Ferres M, Vial P, Marco C, et al. Prospective evaluation of household contacts of persons with hantavirus cardiopulmonary syndrome in chile. The Journal of infectious diseases. Jun 01 2007;195(11):1563-1571.

19. Martinez VP, Bellomo CM, Cacace ML, Suarez P, Bogni L, Padula PJ. Hantavirus pulmonary syndrome in Argentina, 1995-2008. Emerging infectious diseases. Dec 2010;16(12):1853-1860.

20. Khan AS, Ksiazek TG, Peters CJ. Hantavirus pulmonary syndrome. Lancet. Mar 16 1996;347(9003):739-741.

21. Peters CJ, Simpson GL, Levy H. Spectrum of hantavirus infection: hemorrhagic fever with renal syndrome and hantavirus pulmonary syndrome. Annu Rev Med. 1999;50:531-545.

22. Schmaljohn CS. Vaccines for hantaviruses: progress and issues. Expert review of vaccines. May 2012;11(5):511-513.

23. Padula PJ, Rossi CM, Della Valle MO, et al. Development and evaluation of a solid-phase enzyme immunoassay based on Andes hantavirus recombinant nucleoprotein. J Med Microbiol. Feb 2000;49(2):149-155.

24. Bellomo CM, Pires-Marczeski FC, Padula PJ. Viral load of patients with hantavirus pulmonary syndrome in Argentina. Journal of medical virology. Nov 2015;87(11):1823-1830.

25. Garcia M, Iglesias A, Landoni VI, et al. Massive plasmablast response elicited in the acute phase of hantavirus pulmonary syndrome. Immunology. May 2017;151(1):122-135.

26. Iglesias AA, Bellomo CM, Martinez VP. [Hantavirus pulmonary syndrome in Buenos Aires, 2009-2014]. Medicina. 2016;76(1):1-9.

27. Ciancaglini $\mathrm{M}$, Bellomo $\mathrm{CM}$, Torres Cabreros $\mathrm{CL}$, et al. Hantavirus pulmonary syndrome in Tucuman province associated to an unexpected viral genotype. Medicina. 2017;77(2):81-84.

28. MacNeil A, Ksiazek TG, Rollin PE. Hantavirus pulmonary syndrome, United States, 1993-2009. Emerging infectious diseases. Jul 2011;17(7):1195-1201.

29. Kuenzli AB, Marschall J, Schefold JC, et al. Hantavirus Cardiopulmonary Syndrome Due to Imported Andes Hantavirus Infection in Switzerland: A Multidisciplinary Challenge, Two Cases and a Literature Review. Clinical infectious diseases : an official publication of the Infectious Diseases Society of America. May 222018.

30. Kofman A, Eggers $P$, Kjemtrup A, et al. Notes from the Field: Contact Tracing Investigation after First Case of Andes Virus in the United States - Delaware, February 2018. MMWR. Morbidity and mortality weekly report. Oct 19 2018;67(41):1162-1163.

31. Andreo V, Glass G, Shields T, Provensal C, Polop J. Modeling potential distribution of Oligoryzomys longicaudatus, the Andes virus (Genus: Hantavirus) reservoir, in Argentina. Ecohealth. Sep 2011;8(3):332-348.

32. Guerreiro C. Flowering cycles of woody bamboos native to southern South America. Journal of plant research. Mar 2014;127(2):307-313.

33. Oliveira RC, Sant'ana MM, Guterres A, et al. Hantavirus pulmonary syndrome in a highly endemic area of Brazil. Epidemiology and infection. Apr 2016;144(5):1096-1106.

34. Riquelme R, Rioseco ML, Bastidas $L$, et al. Hantavirus pulmonary syndrome, Southern Chile, 1995-2012. Emerging infectious diseases. Apr 2015;21(4):562-568.

This article is protected by copyright. All rights reserved. 
35. Schmaljohn C. Vaccines for hantaviruses. Vaccine. Nov 05 2009;27 Suppl 4:D61-64.

\section{Figures}

Figure 1. Geographical distribution of HPS cases in departments in Argentina, 2009$2017(\mathrm{n}=508)$. Squares indicate cumulative number of cases.

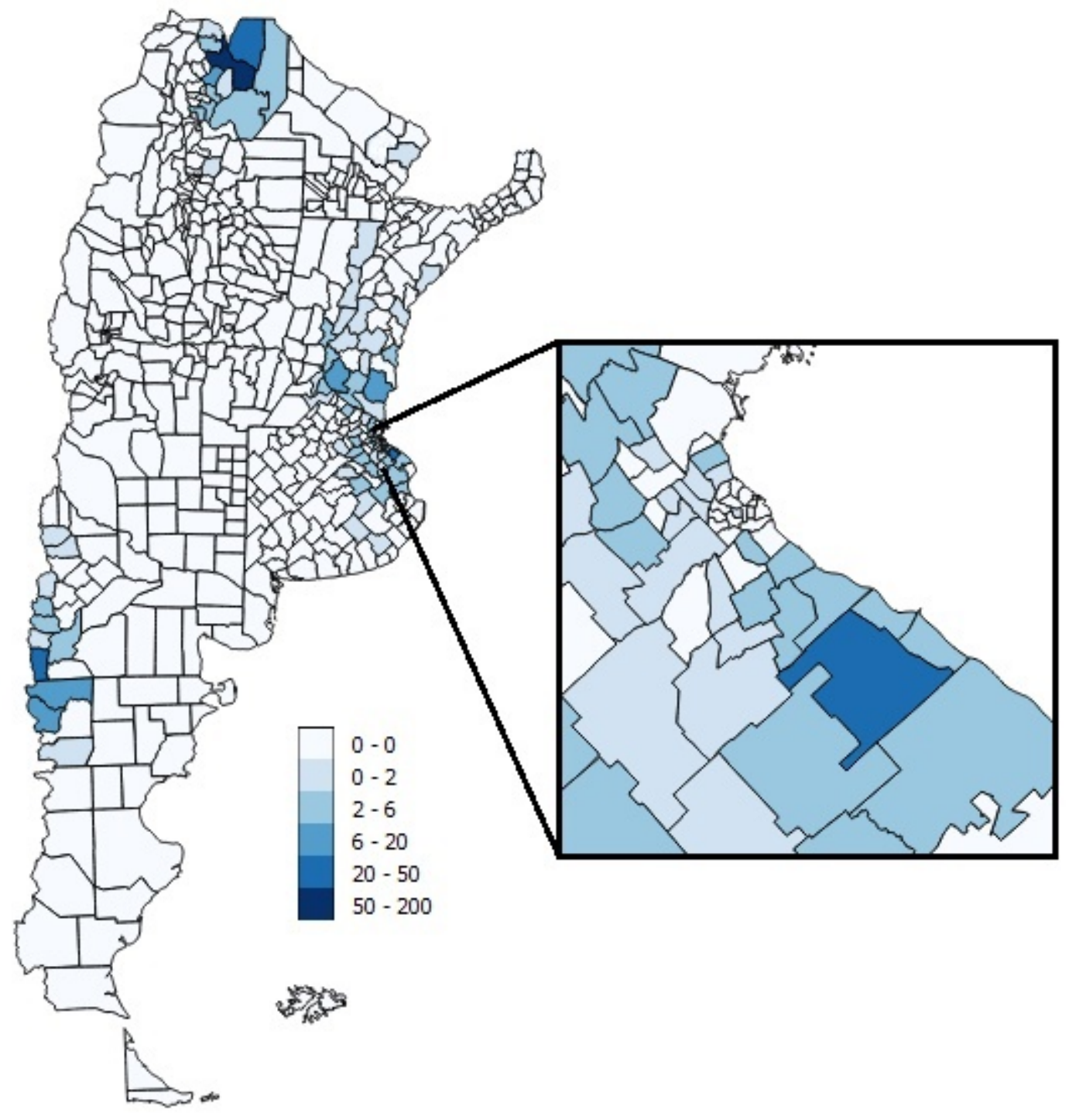

This article is protected by copyright. All rights reserved. 
Figure 2. Temporal HPS case distribution in Argentina, 2009-2017. A) Annual distribution by geographical regions, $n=533$. B) Annual distribution (bars) and casefatality rate (red line), $n=533$. C) Case distribution by month and geographical regions, $\mathrm{n}=503$. $\mathrm{D}$ ) Cumulative number of cases by month, $\mathrm{n}=503$.

A

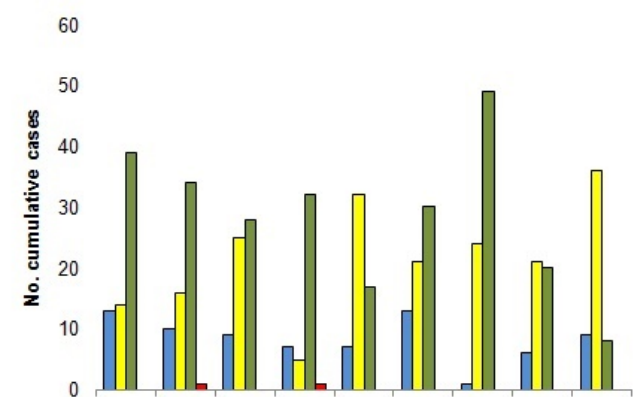

B

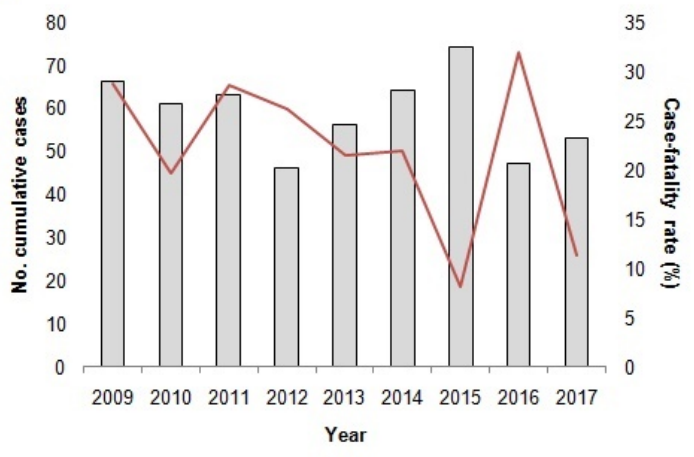

C

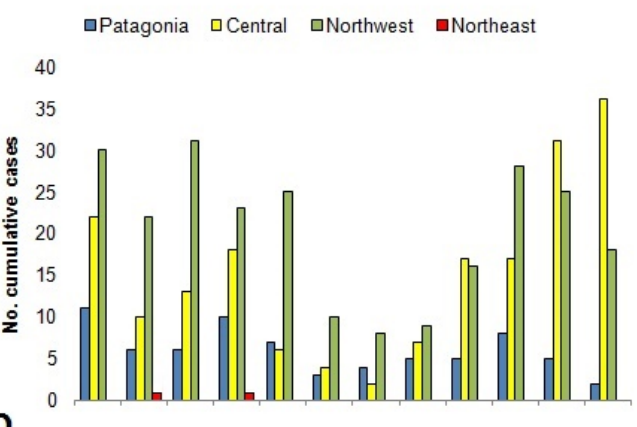

D

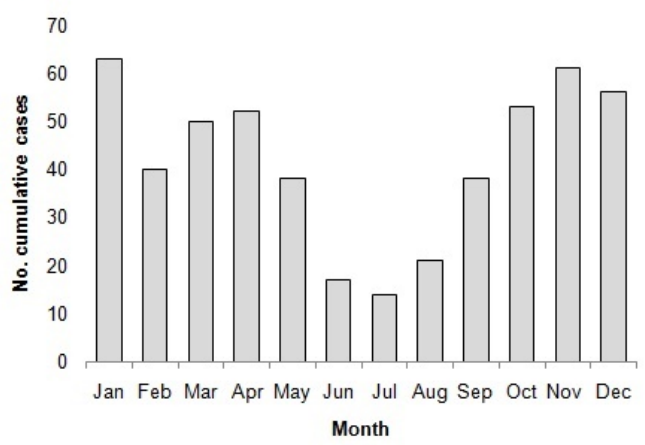

This article is protected by copyright. All rights reserved. 
Figure 3. HPS case distribution by sex and age groups and case fatality rate in Argentina, 2009-2017 $(\mathrm{n}=517)$. White bars and black lines show male patients, red bars and red lines female patients.

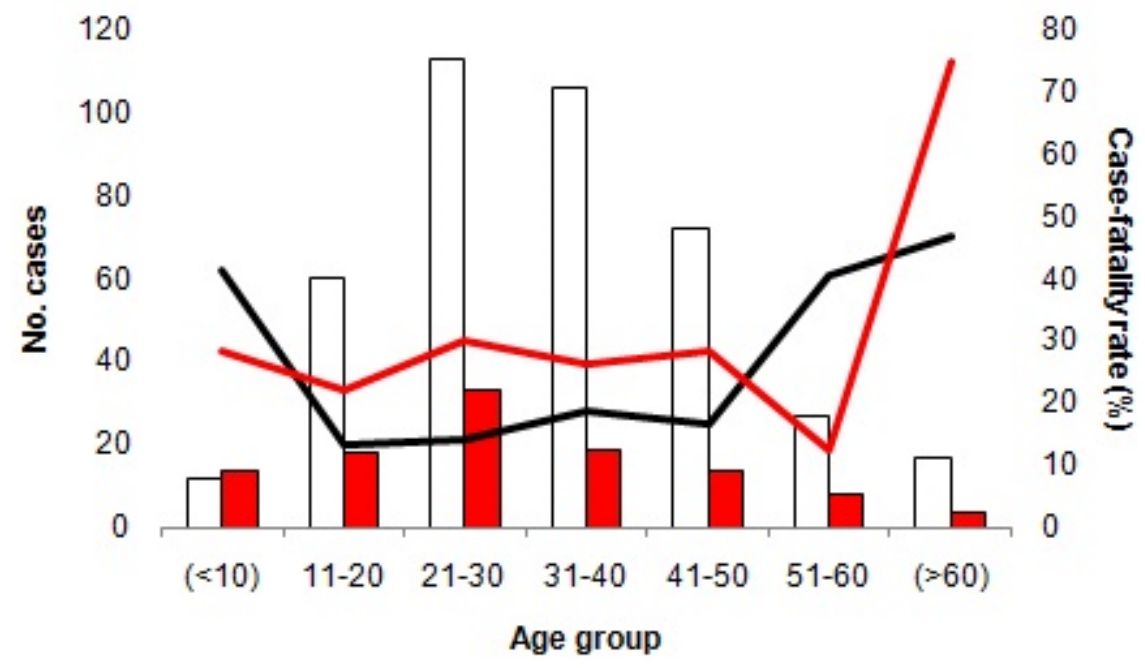

Tables.

Table 1: HPS case patient distribution by geographic regions, Argentina, 2009-2017.

\begin{tabular}{|c|c|c|c|}
\hline Geographic Region & Provinces that reported HPS cases * & $\begin{array}{l}\text { Hantavirus variants circulating in the } \\
\text { regiont }\end{array}$ & $\begin{array}{l}\text { Number of cases in } \\
\text { the present period }\end{array}$ \\
\hline Northwest & Salta, Jujuy, Tucumán & $\begin{array}{l}\text { Andes-Oran, Andes-Bermejo, } \\
\text { Laguna Negra virus }\end{array}$ & 260 \\
\hline Northeast & Corrientes, Formosa & $\begin{array}{l}\text { Andes-Lechiguanas; Andes } \\
\text { Juquitiba }\end{array}$ & 2 \\
\hline Central & $\begin{array}{l}\text { Buenos Aires, Buenos Aires city, } \\
\text { Santa Fé, Entre Ríos }\end{array}$ & $\begin{array}{l}\text { Andes-Lechiguanas; Andes-Buenos } \\
\text { Aires; Andes-Plata }\end{array}$ & 196 \\
\hline Patagonia & Neuquén, Rio Negro, Chubut & Andes-South & 75 \\
\hline
\end{tabular}

\footnotetext{
* Only provinces with $>1$ probable rodent exposure.

† Data provided by previously published studies, period 1995-2017.
}

This article is protected by copyright. All rights reserved. 
Table 2. Clinical classification of HPS cases by severity, Argentina, 20092017.

\begin{tabular}{|c|c|c|c|c|}
\hline \multicolumn{5}{|c|}{ No. case-patients (\%) } \\
\hline Severity Group & Northwest & Central & Patagonia & Total \\
\hline 0 & $3(1.2)$ & 0 & 0 & $3(0.6)$ \\
\hline I & $62(24.2)$ & $12(6.3)$ & $3(4)$ & $77(14.8)$ \\
\hline II & - & $78(41.3)$ & $27(36.5)$ & 165 (31.8) \\
\hline III & - & $37(19.5)$ & $15(20.3)$ & $57(11)$ \\
\hline $\mathrm{II} / \mathrm{III}$ * & $152(59.4)$ & $15(8)$ & $2(2.7)$ & $104(20)$ \\
\hline IV & 39 (15.2) & $47(24.9)$ & $27(36.5)$ & $113(21.8)$ \\
\hline
\end{tabular}

n = 519 (Northwest= 256; Central: 189; Patagonia: 74)

${ }^{*}$ Clinical/Epidemiological form used in the Northwest region did not provide the information required to classify casesamong Grade II or III.

Table 3. Clinical symptoms reported in confirmed HPS cases, Argentina, 2009-2017.

No. case-patients (\%)

Clinical symptoms and findings

Northwest Central Patagonia Tota

Respiratory and circulatory (Cough,

Dyspnoea, Tachypnoea, Shock)

$176(68.6) \quad 177(89.4) \quad 61(89.7)$

414 (79)

Hepatic (hepatomegaly, elevated GOT, GPT, and LDH)

$21(8.2)$

$83(41.5) \quad 25(36.75)$

$129(24.6)$

Renal (elevated levels of creatinine, oligoanuria, renal failure)

$25(9.8)$

45 (22.5)

$22(32.34)$

$92(17.6)$

Hemorrhagic manifestations (Conjunctival injection, Petechiae, Purpura,

$42(16.4)$

$39(19.5)$

$6(8.8)$

87 (19.6)

Hemoptysis, Melena, Epistaxis, etc.)

This article is protected by copyright. All rights reserved. 
Gastrointestinal (Abdominal pain, Vomiting, Diarrhoea)
152 (59.3)

59 (29.5)

$12(17.6)$

223 (42.5)

Neurological (Confusional syndrome,

Seizures, Encephalitis, Meningitis,

Photophobia)

Retro-ocular pain
$11(4.3)$

19 (9.5)

$96(37.4)$
$6(8.82)$

36 (6.9) $\mathrm{n}=524$ (Northwest= 258; Central: 198; Patagonia: 68).

Table 4. Case-fatality rates (by gender) and type of exposure by geographical area.

Case-fatality rates (\%)

\begin{tabular}{|c|c|c|c|c|c|}
\hline Characteristic & Northwest & Central & Patagonia & Northeast & Total \\
\hline $\mathrm{M} \dagger$ & 13.5 & 22.1 & 35.7 & 50 & 19.8 \\
\hline $\mathrm{F}+$ & 20.8 & 31 & 36.8 & - & 27.2 \\
\hline Total & 15 * & 23.9 * & 36 * & 50 & 21.4 \\
\hline & \multicolumn{5}{|c|}{$\mathrm{N}^{\circ}$ of case-patients (\%) } \\
\hline Occupational & $147(64.2)$ & $72(48.7)$ & $27(42.2)$ & - & $246(55.8)$ \\
\hline Recreational & $32(14)$ & $21(14.2)$ & $10(15.7)$ & - & $63(14.3)$ \\
\hline Peridomestic & $50(21.8)$ & $52(35.1)$ & $22(34.3)$ & - & $124(28.1)$ \\
\hline $\begin{array}{c}\text { Contact with previous HPS } \\
\text { case-patient }\end{array}$ & 0 & $3(2)$ & $5(7.8)$ & - & $8(1.8)$ \\
\hline
\end{tabular}

$N^{0}$ of HPS cases per geographic region $(n=533)$. Type of exposure was classified according to most probable risk activities during the estimated incubation period. $(n=441)$ * The fatality rates varied significantly between regions $(p<0.0001$ Chi-square for trends). † Not significant difference was observed in fatality rate associated to sex ( $p$ $<0.0936$ Fisher Exact test).

This article is protected by copyright. All rights reserved. 
Table 5. Molecular epidemiology of HPS cases with recent travel history, Argentina, 2009-2017

\begin{tabular}{|c|c|c|c|c|c|c|}
\hline \multirow{2}{*}{ ID } & \multirow{2}{*}{ Month/Year } & \multicolumn{2}{|c|}{ Residence place } & \multicolumn{2}{|c|}{ Probable site of infection } & \multirow{2}{*}{ Genotype } \\
\hline & & G. Region & City/Province & G. Region & Province & \\
\hline F41 & jan-10 & Central & CABA & Patagonia & Bariloche/RN & ANDV-South \\
\hline F46 & mar-10 & Central & CABA & Central & $\begin{array}{l}\text { Pilar-Tandil/BA; } \\
\text { Gualeguaychú/ER }\end{array}$ & ANDV-BsAs \\
\hline $\mathrm{F} 24$ & feb-12 & Central & San Martin/ER & Patagonia & Bariloche/RN & ANDV-South \\
\hline M42 & jan-13 & Central & CABA & Central & Tigre /BA & ANDV-Lech \\
\hline M28 & apr-13 & Central & CABA & Patagonia & Bariloche/RN & ANDV-South \\
\hline M2 & apr-14 & Central & CABA & Patagonia & Dina Huapi/RN & ANDV-South \\
\hline F56 & jan-14 & Cuyo & Merlo/ SL & Central & Castelli /BA & ANDV-BsAs \\
\hline $\mathrm{F} 26$ & jan-14 & Central & CABA & Patagonia & $\mathrm{RN}, \mathrm{CH}$ & ANDV-South \\
\hline F36 & jan-17 & Cuyo & Mendoza/ME & Central & $\begin{array}{c}\text { Monte Hermoso, } \\
\text { BA }\end{array}$ & ANDV-BsAs \\
\hline M22 & nov-16 & Central & Rosario/SF & Patagonia & $\begin{array}{c}\text { Futaleufú/CH; El } \\
\text { Bolsón/RN; } \\
\text { SMA/NQ }\end{array}$ & ANDV-South \\
\hline M26 & nov-16 & Central & San Isidro/BA & Central/Northwest & $\begin{array}{l}\text { Campana/BA; } \\
\text { LGSM/Jujuy; } \\
\text { Tartagal/Salta }\end{array}$ & ANDV-Oran \\
\hline M18 & feb-17 & Central & CABA & Patagonia & Bariloche/RN & ANDV-South \\
\hline
\end{tabular}

BA: Buenos Aires; CABA: Ciudad Autónoma de Buenos Aires; ER: Entre Rios; RN: Rio Negro; CH: Chubut; SL: San Luis; SMA: San Martín de los Andes; TU:Tucuman; LGSM: Libertador General San Martin; ME: Mendoza; Santa Fe; NQ: Neuquen.

This article is protected by copyright. All rights reserved. 